\title{
Influence of Test Parameters on Release Rate of Hydrocortisone from Cream: Study Using Vertical Diffusion Cell
}

\author{
Preethi Naik ${ }^{1,{ }^{\dagger}}$, Sanket M. Shah ${ }^{1,{ }^{\dagger}}$, John Heaney ${ }^{2}$, Royal Hanson ${ }^{2}$, and Mangal S. Nagarsenker ${ }^{1, *}$ \\ ${ }^{1}$ Department of Pharmaceutics, Bombay College of Pharmacy, Kalina, Santacruz (East), Mumbai-400098, India \\ ${ }^{2}$ Hanson Research Corporation, 9810 Variel Ave., Chatsworth, CA 91311
}

e-mail:mangal.nagarsenker@bcp.edu.in; mangal_nag511@yahoo.co.in

\section{ABSTRACT}

Vertical diffusion cells (VDC) have been envisaged as in vitro surrogates for ensuring product quality and performance for topical preparations. USP General Chapter $<1724>$ Semisolid Drug Products-Product Performance Tests describes the application of VDC as one of the apparatus required for in vitro testing of topical products. Knowledge of various operational parameters and their impact on drug release during diffusion experiments thus becomes imperative. In the present study, parameters like temperature, composition of receptor medium, speed of stirring, and filled volume of cell jacket have been evaluated for their influence on drug release rate from hydrocortisone cream employing vertical diffusion cells. The statistical analysis of the results was performed by one-way ANOVA with Bonferroni post hoc test. Results suggest that the composition of the receptor medium significantly influences drug release from cream, and slower stirring rates translate to lower release rates. On the other hand, within experimental design, the temperature of the receptor and filled condition of the cell jacket do not influence drug release significantly.

KEYWORDS: Hydrocortisone cream; vertical diffusion cell; in vitro release of topicals; dissolution.

\section{INTRODUCTION}

$\mathrm{D}$ rug delivery systems administered through routes other than oral have gained popularity in recent times. For over a decade, researchers have envisaged delivery via a skin/topical route as an attractive arena for drug delivery. While most topical dosage forms are developed for local action, systemic delivery of drugs is achieved through transdermal systems $(1,2)$. Drugs like scopolamine, nitroglycerin, nicotine, clonidine, fentanyl, estradiol, testosterone, lidocaine, vitamin B12, and others are delivered transdermally and have been commercially successful (3). Transdermal systems deliver the drug through different layers of the skin into systemic circulation. The important advantages of transdermal delivery systems over conventional oral solid dosage forms (OSDs) are the bypass of first-pass metabolism and better patient compliance especially in cases where OSDs are not possible (4). An essential property of such a carrier is the release of drug into the contact epidermal surface in sufficient amounts before movement to the dermis and subsequent absorption into the blood. Hence, monitoring the drug release rate is an important quality control parameter in the development of transdermal dosage forms. It is important to ensure reproducible and reliable release of drug from each tested product. For many years, the Franz diffusion cell (FDC) has been employed as the primary evaluation tool for assessing drug release from semisolid dosage forms (5). It enables quantification of the amount of drug that permeates across a membrane using components that mimic the travel of the active pharmaceutical ingredient (API) through skin. An FDC has a donor compartment, a receptor compartment, and a barrier to mimic skin. The barrier can be an artificial membrane like polysulfone, cellulose mixed esters, polytetrafluoroethylene, polypropylene, and others or natural like pigskin, rat skin, or human skin (6). The advantages of artificial membranes for method development are reproducibility, absence of biological variability, easier setup, and low cost.

The vertical diffusion cell (VDC) is a refinement of the FDC with minor design changes that provide better control over stirring owing to the presence of a helix on the stirring bar. In addition, sampling is based on a positive displacement technique that makes aliquot withdrawal and replacement easier and more effective. It provides for a robust, reliable, and reproducible methodology for testing drug release (7). The FDA SUPAC guidance (8)

\footnotetext{
Contributed equally to this work.

* Corresponding author. 
recommends VDC for assessing scale-up and postapproval changes in semisolid dosage forms. A new USP General Chapter <1724> Semisolid Drug Products-Product Performance Tests (9) is referenced for performance validation of topical and transdermal products. It describes the application of the vertical diffusion cell as one of the apparatus recommended for in vitro testing of topical products. Thus VDCs have been in vitro surrogates for ensuring product quality and performance maintenance over time and product changes. An in vitro release rate from a semisolid dosage form reflects the presence of the correct polymorphic form of an API, its solubility, and its particle size apart from the rheological property of the dosage form. Any change in the in vitro release rate profile is an indication of a change in an important physical or chemical property of the semisolid dosage form. An in vitro release rate test can also be used as an assessment tool to ascertain whether any change in the process or manufacturing site affects the release of the API from the semisolid dosage form. The absence of a significant change in the release rate profile of the API, indicates that the suggested process changes does not affect the overall quality of the semisolid dosage form (5).

The FDA guidance on nonsterile dosage forms for in vitro release testing and in vivo bioequivalence documentation (8) suggests different scale-up and post approval changes that can affect the product quality attributes due to changes in components and composition, changes in manufacturing, and changes in batch size. The guidance also provides the procedure for in vitro release testing to rule out any possibility of a change in product quality attributes. The aim of this study was to vary the operational parameters of VDCs such as (1) cell temperature $(30,32$, and $\left.34{ }^{\circ} \mathrm{C}\right)$; (2) rotation speed $(1000,800$, and $200 \mathrm{rpm})$; (3) receptor medium composition $(10,20$, and $30 \% \mathrm{v} / \mathrm{v}$ alcohol/water); and (4) jacket filling capacity and compare the drug release results using one-way ANOVA. Thus, the experiments included the evaluation of one process parameter and two instrument parameters, each at three levels, and another instrument parameter at two levels as summarized in Table 1.

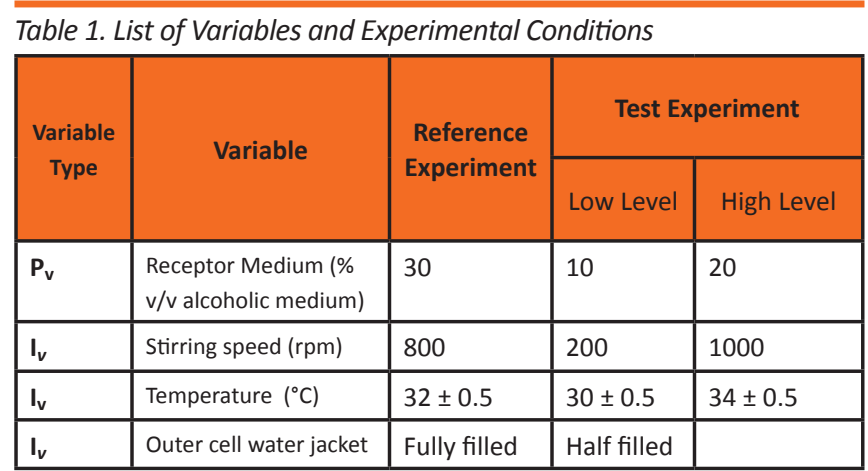

$P v=$ Process variable; $I v=$ instrument variable $(n=3)$

\section{MATERIALS AND METHODS}

\section{Materials and Reagents}

USP Hydrocortisone Reference Standard was purchased from Alfa Aesar (Johnson Matthey Company, USA). Materials used were acetonitrile HPLCgrade (Merck, India), absolute ethanol (S.D. Fine Chemicals, India), polysulfone Tuffryn $0.45-\mu \mathrm{m}$ membrane (Pall Corporation, India), and Milli-Q water type I (Millipore, India). A commercially available topical cream containing $1 \%$ hydrocortisone was used for the study (Cortisone, CVS Corp., USA).

\section{Instruments}

Hanson vertical diffusion cells (part \#58-001-455) were employed for diffusion experiments. HPLC analysis of hydrocortisone was performed using a Waters $\mathrm{C}_{18}$ column ( $50 \mathrm{~mm}, 3.9 \mathrm{~mm} \times 5 \mu \mathrm{m}$, Waters, India), a JASCO PU-2089 Plus quaternary pump, JASCO AS-2055 Plus intelligent sampler, and JASCO MD-2018 Plus photodiode array detector (Jasco corporation, Japan). Chromatograms were recorded and processed using ChromNAV CFR v1.18.06 software.

\section{Analytical Method}

An HPLC method described previously (9) was employed. Hydrocortisone $(\mathrm{HC})$ was analyzed from the in vitro release samples. The mobile phase was $\mathrm{ACN}-$ water (20:80), and the flow rate was $1 \mathrm{~mL} / \mathrm{min}$. The injection volume was $10 \mu \mathrm{L}$. During analysis, the in vitro release samples were bracketed between standard injections to eliminate ghost effects.

\section{In Vitro Release Test}

The six-cell manual testing system, comprising cells with an orifice diameter of $15 \mathrm{~mm}$ and a nominal cell volume of $7 \mathrm{~mL}$, was used for the study. Each of these cells was housed in a stainless steel holder plate. A magnetic plate with six stirring points was accommodated in the holder plate such that center of the stirrer coincided with the center of the cell. Magnetic stirring bars and helixes were placed in the receptor compartments and filled with degassed medium (water-USP alcohol 95\%). The outer jackets of the six cells were connected in series and were attached to a water bath (Polyscience, Germany). To maintain cell temperature, water at $0.5^{\circ} \mathrm{C}$ higher than the desired temperature was circulated throughout the cell jacket of the six cells. Tuffryn membrane presoaked in receptor medium for $30 \mathrm{~min}$ was mounted between the donor and receptor compartments. Samples were withdrawn periodically at $1,2,3,4$, and $6 \mathrm{~h}$ by a positive displacement technique. Stirring was switched off during sampling. The diffusion of $\mathrm{HC}$ from the cream across this membrane into the receiving medium was evaluated by the aforementioned HPLC method. A plot of the average 


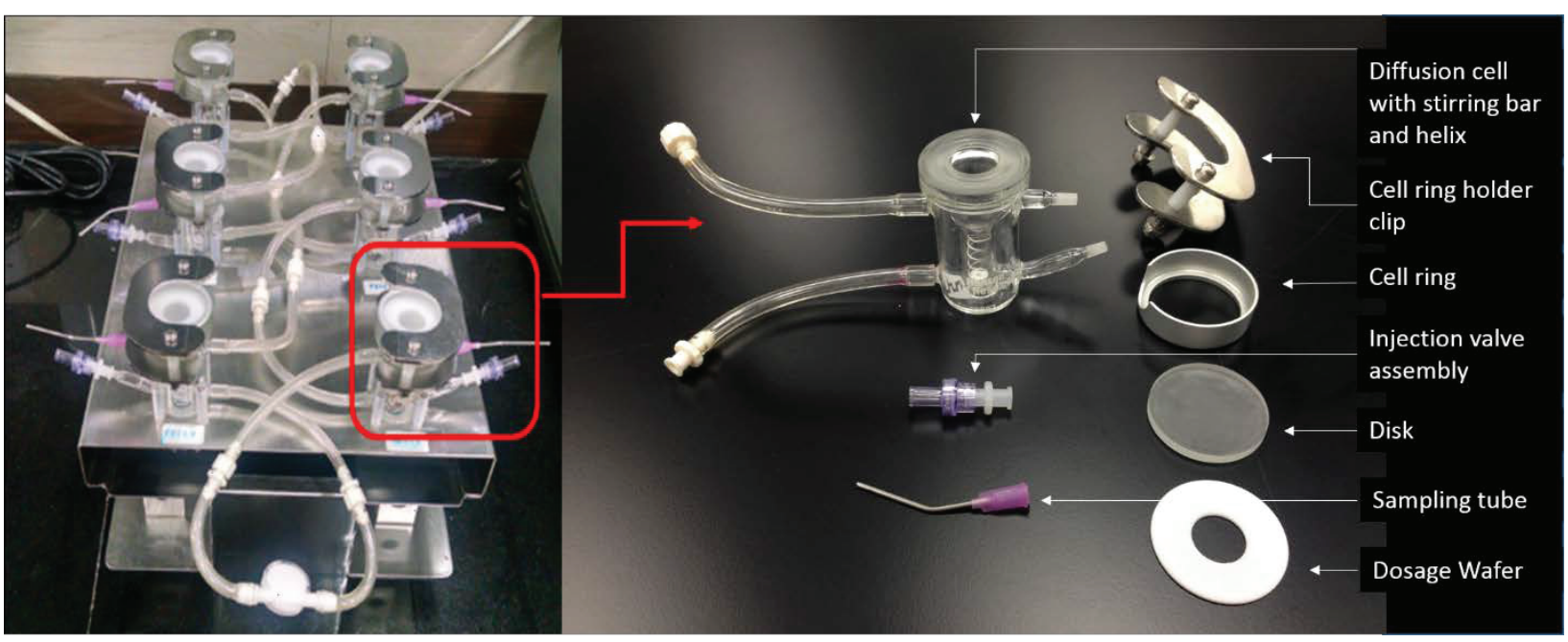

Figure 1. Experimental setup of six diffusion cells in series. Inset: Vertical diffusion cell assembly and accessories.

amount of $\mathrm{HC}$ released versus the square root of time was developed. The complete setup of the apparatus is shown in Figure 1.

To accommodate variations due to slight differences in the design of the six cells, reference experiments were performed. Experimental conditions of the reference and test experiments are summarized in Table 1. Each run was performed in triplicate.

\section{Statistical Analysis}

The statistical analysis of the results was performed by one-way ANOVA with Bonferroni post hoc test employing software GraphPad Prism version 5.00 (GraphPad Software Inc., USA). The average release rate $(\mu \mathrm{g} /$ $\mathrm{cm}^{2} / \mathrm{min}^{1 / 2}$ ) of $\mathrm{HC}$ from the cream was chosen as the response for analysis. The univariate ANOVA applied on the reference experiment allowed monitoring of intercell variation (Table 2). In addition, evaluation of the effect of operational parameters on the release rate of $\mathrm{HC}$ from the cream formulation was performed by applying ANOVA to the average release rate of six cells at all levels of variation of operational parameters (Table 3 ).

In the present study, in vitro release profiles of $1 \%$ hydrocortisone cream in reference and test experiments were compared in accordance with FDA guidelines for SUPAC-SS. The experiment carried out at $32{ }^{\circ} \mathrm{C}, 800$ rpm, with a medium of $30 \%$ alcohol was considered the reference experiment, and experiments performed with the parameters varied were referred as test. The reference slope $(R)$ was obtained from a plot of amount released versus the square root of time from the reference experiment. Test slopes $(T)$ were determined similarly from test experiments. $T / R$ ratios were calculated for each test slope. After the $T / R$ ratios were calculated, they were ordered from lowest to highest. For performance validation testing with $90 \%$ confidence, the 8 th and 29 th $T / R$ ratios, when expressed as percentages, must fall within $75-133.33 \%$ (8).

Table 2. Results of ANOVA for Intercell Variation

\begin{tabular}{|c|c|c|}
\hline \multicolumn{3}{|c|}{ One way ANOVA: 6 diffusion cells } \\
\hline \multicolumn{3}{|c|}{ Reference experiment $(n=3)$} \\
\hline \multicolumn{2}{|c|}{ Are the means significantly different? } & NO \\
\hline \multicolumn{3}{|c|}{ Bonferroni multiple comparison } \\
\hline 1 vs 2 & NS & $P>0.05$ \\
\hline 1 vs 3 & NS & $P>0.05$ \\
\hline 1 vs 4 & NS & $P>0.05$ \\
\hline 1 vs 5 & NS & $P>0.05$ \\
\hline 1 vs 6 & NS & $P>0.05$ \\
\hline 2 vs 3 & NS & $P>0.05$ \\
\hline 2 vs 4 & NS & $P>0.05$ \\
\hline 2 vs 5 & NS & $P>0.05$ \\
\hline 2 vs 6 & NS & $P>0.05$ \\
\hline 3 vs 4 & NS & $P>0.05$ \\
\hline 3 vs 5 & NS & $P>0.05$ \\
\hline 3 vs 6 & NS & $P>0.05$ \\
\hline 4 vs 5 & NS & $P>0.05$ \\
\hline 4 vs 6 & NS & $P>0.05$ \\
\hline 5 vs 6 & NS & $P>0.05$ \\
\hline
\end{tabular}

\section{RESULTS}

The HPLC method was validated with respect to linearity and precision. The retention time for the $\mathrm{HC}$ peak was approximately $7 \mathrm{~min}$. System suitability was checked by 
Table 3. ANOVA Results Applied to Study the Effect of Operational Parameter Variations on Release Rate

\begin{tabular}{|c|c|c|c|c|c|}
\hline \multicolumn{3}{|c|}{$\begin{array}{l}\text { 1. One-way ANOVA: Temperature } \\
\qquad(n=3)\end{array}$} & \multicolumn{3}{|c|}{$\begin{array}{l}\text { 2. One-way ANOVA: Jacketed conditions } \\
\qquad(n=3)\end{array}$} \\
\hline Are the means $\mathrm{s}$ & different? & NO & Are the means si & different? & NO \\
\hline \multicolumn{3}{|c|}{ Bonferroni multiple comparison } & \multicolumn{3}{|c|}{ Bonferroni multiple comparison } \\
\hline 30 vs 32 & NS & $P>0.05$ & \multirow{3}{*}{$\begin{array}{l}\text { Half vs fully filled } \\
\text { jacket }\end{array}$} & \multirow{3}{*}{ NS } & \multirow{3}{*}{$P>0.05$} \\
\hline 32 vs 34 & NS & $P>0.05$ & & & \\
\hline 30 vs 34 & NS & $P>0.05$ & & & \\
\hline \multicolumn{3}{|c|}{$\begin{array}{l}\text { 3. One-way ANOVA: rpm } \\
\qquad(n=3)\end{array}$} & \multicolumn{3}{|c|}{$\begin{array}{l}\text { 4. One-way ANOVA: Medium composition } \\
\qquad(n=3)\end{array}$} \\
\hline Are the means $\mathrm{s}$ & different? & Yes & Are the means si & different? & Yes \\
\hline \multicolumn{3}{|c|}{ Bonferroni multiple comparison } & \multicolumn{3}{|c|}{ Bonferroni multiple comparison } \\
\hline 200 vs 800 & $\mathrm{~S}$ & $P<0.05$ & 10 vs 30 & $\mathrm{~s}$ & $P<0.05$ \\
\hline 800 vs 1000 & NS & $P>0.05$ & 20 vs 30 & $\mathrm{~s}$ & $P<0.05$ \\
\hline 200 vs 1000 & S & $P<0.05$ & 10 vs 20 & $\mathrm{~S}$ & $P<0.05$ \\
\hline
\end{tabular}

$N S=$ Not significant; $S=$ Significant

periodic injections of a standard $\mathrm{HC}$ solution, bracketing the samples throughout the run. A relative standard deviation of less than $2 \%$ for the peak area for the standard solution injections was achieved for each run. The peak areas for $\mathrm{HC}$ for in vitro release samples were recorded and used in calculation of the amount released per unit area of membrane $\left(\mu \mathrm{g} / \mathrm{cm}^{2}\right)$. The steady state of flux was determined from the slope of the plot of amount released per unit area versus the square root of time. The linear nature of the plot $\left(R^{2}=0.99\right)$ suggests that the release of drug from cream followed the Higuchi model (10). The result of the reference experiment is depicted in Figure 2.

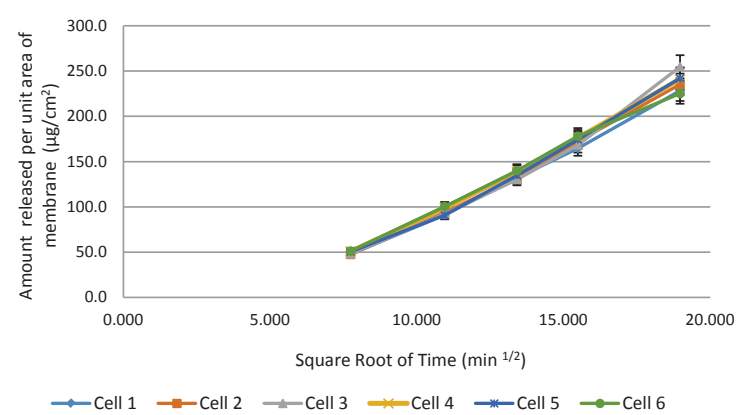

Figure 2. Plots of drug release profiles of six diffusion cells. Data represented as mean $\pm S D(n=3)$.

Statistical analysis by univariate ANOVA helped to assess whether variations in operational parameters under consideration significantly altered the release rate of drug from the formulation, while the Bonferroni multiple comparison test assessed which operational parameters under consideration significantly affected drug release. As evidenced from Table 2, the result of one-way ANOVA of the reference experiment revealed that there was consistency in the performance of the six diffusion cells and that there was no significant difference in the release profiles.

Table 3 shows that operational variables, namely stirring speed and medium composition, significantly affected the release rate of $\mathrm{HC}$ from the cream, while temperature and filled condition of the cell jacket had little influence. Apparent differences in the release patterns of the six cells were noted at different temperatures, but these observations were statistically not significant. In Figure 3, the curves corresponding to higher stirring speeds (800 and $1000 \mathrm{rpm}$ ) are contiguous and exhibit release profiles similar to the plot at $200 \mathrm{rpm}$. Thus, a lower stirring speed resulted in slower and lower extent of $\mathrm{HC}$ release. The influence of medium composition was most profound. An increase in alcohol concentration increased the rate and extent of $\mathrm{HC}$ release. The rate of $\mathrm{HC}$ release from the cream followed the order of $10 \%<20 \%<30 \%(\mathrm{v} / \mathrm{v})$ alcohol 95\%. The filled condition of cell jacket did not significantly influence $\mathrm{HC}$ release from the cream.

The equivalence of reference and test samples for different changes in operational parameters and their compliance with FDA SUPAC-SS guidelines has been summarized in Table 4. A lower stirring speed (200 rpm) and variation in the composition of the receptor medium failed to pass Stage 1 of FDA SUPAC-SS requirements at the $90 \%$ confidence interval. 

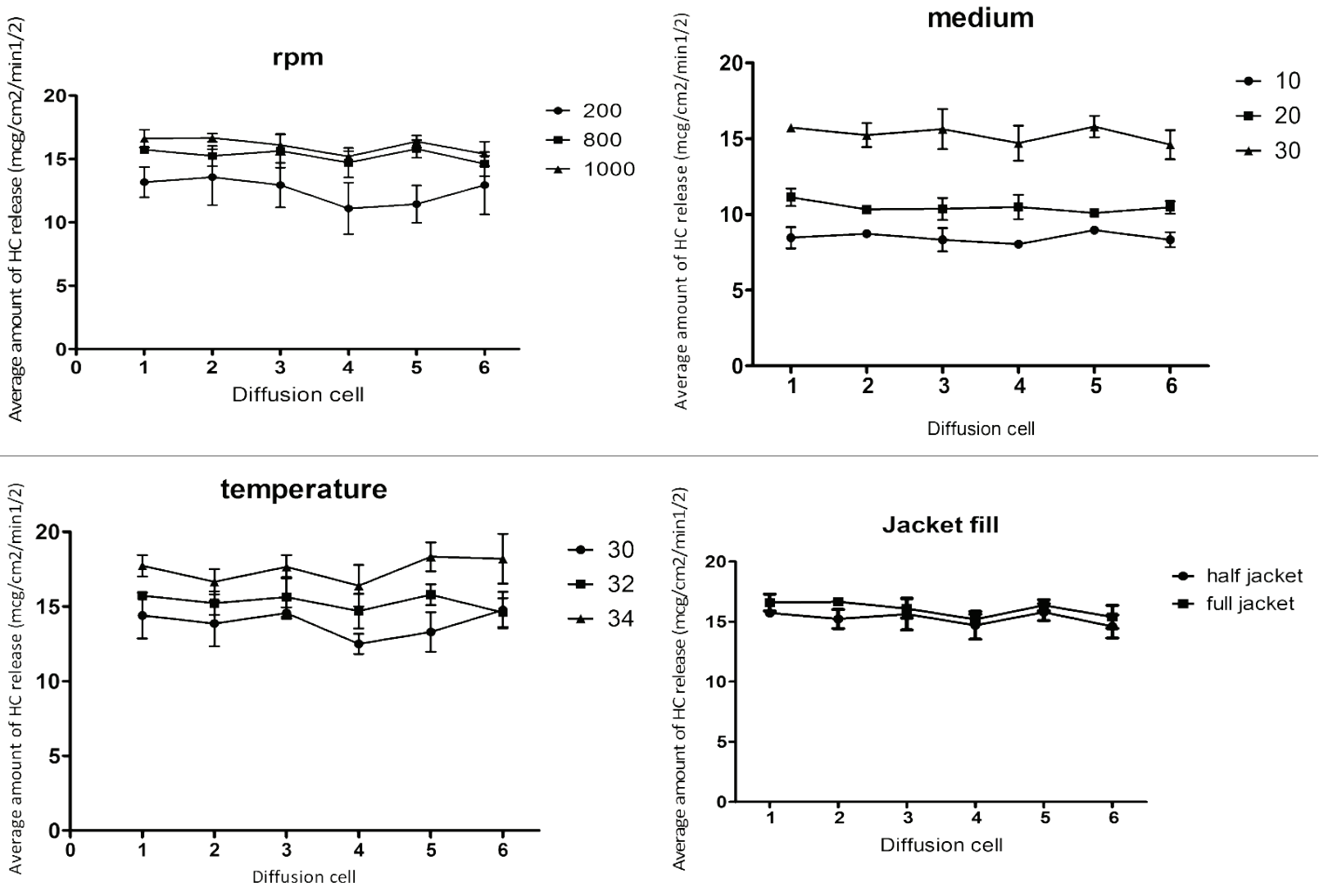

Figure 3. Results of variations in operational parameters and their influence on the release rate of HC. Data represented as mean $\pm S D(n=3)$.

\section{DISCUSSION}

The results indicate that the major contributor to the diffusion of $\mathrm{HC}$ across an artificial membrane on a VDC is the composition of receptor fluid, followed by the rotation speed, and the temperature of the receptor fluid. This is a very significant and logical conclusion as it emphasizes the importance of receptor fluid composition for using VDCs to evaluate semisolid dosage forms. The receptor fluid should have enough solubilization power for a positive transport of the drug from the donor compartment to the receptor compartment through the artificial/bio membrane. This will ensure that a plateau in diffusion of drug is not reached prematurely as such a situation can show a poor diffusion for a good formulation. As a rule of thumb, the composition of receptor medium is chosen such that not more than $30 \%$ of the total amount of drug loaded is released into the receptor compartment at the end of study $(11,12)$. Under such conditions, the amount of drug release per unit area is proportional to the square root of time exhibiting a Higuchi model release profile $(10,12)$. In addition, while employing hydroalcoholic solutions as release media, the content of alcohol has to be chosen judiciously so that diffusional sink conditions are maintained allowing sufficient drug release over a substantial time period for accurate analysis, and the alcohol should not alter formulation characteristics due to back diffusion into the donor compartment. A high solubilization power of the receptor fluid could lead to enhanced flux from the donor compartment and may reduce the discriminating power of the method. Shah et al. (11) have reported that the release rate for betamethasone dipropionate from creams ranged between 0.61 and $2.68 \mu \mathrm{g} / \mathrm{cm}^{2} / \mathrm{min}^{1 / 2}$ depending on the percentage of ethanol in the receptor medium. The study indicates that the discriminating power of the method decreased as the ethanol content in the release medium was increased from $30 \%$ to $60 \%$. Thus, appropriate composition of receptor fluid is vital to the success of in vitro release testing and can give precise evaluation of the diffusion kinetics of the semisolid dosage form. The release medium for $\mathrm{HC}$ cream used in previous studies was a $30 \%(\mathrm{v} / \mathrm{v})$ alcoholic solution $(7,13)$. The present study explores the influence of perturbations in receptor medium composition on $\mathrm{HC}$ release. The impact of variation in receptor medium composition on $\mathrm{HC}$ release profile was significant. This could be attributed to 
Table 4. In Vitro Release Results of HC Cream with Changes in Operational Parameter to Evaluate Equivalence with Reference Experiments

\begin{tabular}{|c|c|c|c|c|}
\hline Test & Variable parameters & 8th $T / R$ ratio (\%) & 29th T/R ratio (\%) & $\begin{array}{c}\text { Pass/fail as per FDA SUPAC- } \\
\text { SS (stage 1a) }\end{array}$ \\
\hline \multicolumn{5}{|c|}{ Reference experiment: $32{ }^{\circ} \mathrm{C}, 800 \mathrm{rpm}, 30 \%$ ethanolic medium, fully filled jacket } \\
\hline \multirow{6}{*}{ Temperature variation } & \multirow{3}{*}{30} & 84.7 & 93.8 & \multirow{3}{*}{ Pass } \\
\hline & & 92 & 104.4 & \\
\hline & & 67.9 & 96.2 & \\
\hline & \multirow{3}{*}{34} & 105.2 & 119.5 & \multirow{3}{*}{ Pass } \\
\hline & & 90.9 & 101.9 & \\
\hline & & 112 & 129 & \\
\hline \multirow{6}{*}{ Stirring speed variation } & \multirow{3}{*}{200} & 54 & 72.4 & \multirow{3}{*}{ Fail } \\
\hline & & 70.3 & 94.5 & \\
\hline & & 84.2 & 98.8 & \\
\hline & \multirow{3}{*}{1000} & 97.1 & 108.6 & \multirow{3}{*}{ Pass } \\
\hline & & 95.1 & 108.5 & \\
\hline & & 87.8 & 99.4 & \\
\hline \multirow{6}{*}{$\begin{array}{l}\text { Variation in Composition of } \\
\text { medium }\end{array}$} & \multirow{3}{*}{10} & 43.6 & 54.9 & \multirow{3}{*}{ Fail } \\
\hline & & 50.9 & 57.4 & \\
\hline & & 50.3 & 57.1 & \\
\hline & \multirow{3}{*}{20} & 61.8 & 72.2 & \multirow{3}{*}{ Fail } \\
\hline & & 57.1 & 64.5 & \\
\hline & & 61.1 & 72.4 & \\
\hline \multirow{3}{*}{ Filled condition of jacket } & \multirow{3}{*}{ half } & 79.4 & 90.2 & \multirow{3}{*}{ Pass } \\
\hline & & 87.9 & 94.9 & \\
\hline & & & 100 & \\
\hline
\end{tabular}

${ }^{a}$ Stage 1 means two tests of 6 cells must pass the FDA SUPAC-SS criterion for $90 \%$ confidence interval.

the higher flux facilitated by ethanol in the medium owing to excellent solubility of $\mathrm{HC}$ in ethanol, which is $15 \mathrm{mg} /$ $\mathrm{mL}$, compared with $0.3 \mathrm{mg} / \mathrm{mL}$ in water (14). Alcoholic medium showed a positive effect on $\mathrm{HC}$ release (i.e., the higher the alcohol content in the medium, the faster the release rate due to the increased concentration gradient between the receptor and the donor compartment). Shah and coworkers $(11,15)$ showed that $30 \%$ ethanolic medium was sufficient to maintain diffusional sink conditions while not adversely affecting the integrity of the dosage form.

The speed of rotation in the current study did show a measurable effect on the diffusion of $\mathrm{HC}$ across an artificial membrane. The correct choice of stirring rate is a prerequisite for reliable and reproducible diffusion results. The relationship of the amount of drug released to the square root of time as per Higuchi release kinetics is based on the assumption of the existence of a stagnant drug layer closer to the membrane (10). Disturbances in the thickness of the drug-saturated layer may reflect in variability in diffusion. A very low rotation speed can lead to the presence of pockets of low drug and high drug concentration resulting in variability in diffusion. In the current study, the use of a helix atop a magnetic stirring bar ensured that stirring was uniform and that small variations in rotation speed did not affect the diffusion kinetics. Kikwai et al. (13) reported that no statistical significance was observed for $\mathrm{HC}$ release from $1 \% \mathrm{HC}$ cream when the stirring speed was varied over the range of 600-800 rpm. Similarly, in the present study, variability differences in the $\mathrm{HC}$ release were not significant between 800 and $1000 \mathrm{rpm}$ within the experimental limit of rpm. However, a large deviation was observed at the slow speed of $200 \mathrm{rpm}$. While not observed in this study, significantly higher speeds may result in an unintended change of drug release.

In the present study, $\mathrm{a} \pm 2{ }^{\circ} \mathrm{C}$ change in temperature did not result in any significant differences in $\mathrm{HC}$ diffusion. It is suggested that an increase in temperature leads to an increase in diffusion, as temperature increases the solvent power of the receptor fluid and vice versa. This hypothesis was validated in the current study where the diffusion is lowest at $30^{\circ} \mathrm{C}$ and highest at $34{ }^{\circ} \mathrm{C}$, albeit without any significant difference in diffusion.

|Dissolution 


\section{CONCLUSION}

The current study explores the major factors influencing diffusion kinetics. The experiments establish that changes in the receptor fluid composition will have a direct effect on the diffusion of the API across the artificial membrane of a VDC. Speed of rotation also influences the diffusion process due to its effect on the barrier of unstirred layers. Changes in temperature or changes in jacket filling within experimental limit have little impact on the overall diffusion process used in the current study. The inferences of the study can be used to design, perform, and validate diffusion methods for new semisolid dosage forms keeping in mind the major influencing parameters of diffusion.

\section{ACKNOWLEDGEMENT}

The authors thank LabIndia Instruments Pvt Ltd, India, for providing the support in procurement of Hanson vertical diffusion cells.

\section{CONFLICT OF INTEREST}

The study was supported in part by Hanson Research Corporation. Authors Preethi Naik, Sanket M. Shah, and Mangal S. Nagarsenker have no conflict of interest.

\section{REFERENCES}

1. Garg, T.; Rath, G.; Goyal, A. K. Comprehensive review on additives of topical dosage forms for drug delivery. Drug Delivery 2014, 22 (8), 1-19. DOI: 10.3109/10717544.2013.879355.

2. Upadhyay, G.; Verma, S.; Parvez, N.; Sharma, P. K. Recent Trends in Transdermal Drug Delivery System-A Review. Adv. Biol. Res. 2014, 3, 131-138. DOI: 10.5829/idosi.abr.2014.8.3.8446.

3. Prausnitz, M. R.; Mitragotri, S.; Langer, R. Current status and future potential of transdermal drug delivery. Nat. Rev. Drug Discovery 2004, 3 (2), 115-124. DOI: 10.1038/nrd1304.

4. Allen, L. V.; Ansel, H. C. Ansel's Pharmaceutical Dosage Forms and Drug Delivery Systems, 10th ed.; Lippincott Williams \& Wilkins: Baltimore, MD, 2014.

5. Klein, S. Influence of different test parameters on in vitro drug release from topical diclofenac formulations in a vertical diffusion cell setup. Pharmazie 2013, 68 (7), 565-571. DOI: 10.1691/ph.2013.6528.

6. Christensen, J. M.; Chuong, M. C.; Le, H.; Pham, L.; Bendas, E.
Hydrocortisone Diffusion Through Synthetic Membrane, Mouse Skin, and Epiderm ${ }^{\text {TM }}$ Cultured Skin. Arch. Drug Inf. 2011, 4 (1), 10-21. DOI: 10.1111/j.1753-5174.2010.00033.x.

7. Hauck, W. W.; Shah, V. P.; Shaw, S. W.; Ueda, C. T. Reliability and Reproducibility of Vertical Diffusion Cells for Determining Release Rates from Semisolid Dosage Forms. Pharm. Res. 2007, 24 (11), 2018-2024. DOI: 10.1007/s11095-007-9329-x.

8. SUPAC-SS: Nonsterile Semisolid Solid Oral Dosage Forms, ScaleUp and Postapproval Changes: Chemistry, Manufacturing, and Controls; In Vitro Dissolution Testing and In Vivo Bioequivalence Documentation; Guidance for Industry; Guidance for Industry; U.S. Department of Health and Human Services, Food and Drug Administration, Center for Drug Evaluation and Research (CDER), U.S. Government Printing Office: Washington, DC, 1997.

9. <1724> Semisolid Drug Products-Performance Tests. In The United States Pharmacopeia and National Formulary USP 37-NF 32; The United States Pharmacopeial Convention, Inc.: Rockville, MD, 2014; pp 1273-1284.

10. Higuchi, T. Physical chemical analysis of percutaneous absorption process from creams and ointments. J. Soc. Cosmet. Chem. 1960, 11, 85-97.

11. Shah, V. P.; Elkins, J. S.; Williams, R. L. Evaluation of The Test System Used for In Vitro Release of Drugs for Topical Dermatological Drug Products. Pharm. Dev. Technol. 1999, 4 (3), 377-385. DOI: 10.1081/PDT-100101373.

12. Thakker, K. D.; Chern, W. H. Development and Validation of In Vitro Release Tests for Semisolid Dosage Forms-Case Study. Dissolution Technol. 2003, 10 (2), 10-15. DOI: 10.14227/ DT100203P10.

13. Kikwai, L.; Tran, D.; Hauck, W. W.; Shah, V. P.; Stippler, E. S. Effect of Various Operational Parameters on Drug Release from a 1\% Hydrocortisone Semisolid Dosage Form Using the Vertical Diffusion Cell Apparatus. Dissolution Technol. 2012, 19 (3), 6-13. DOI: 10.14227/DT190312P6.

14. Cortisol. PubChem Open Chemistry Database Web site. http:// pubchem.ncbi.nlm.nih.gov/compound/5754 (accessed June 22, 2016).

15. Shah, V. P.; Williams, R. L. Importance of In Vitro Drug Release. In Topical Drug Bioavailability, Bioequivalence, and Penetration; Springer: New York, 2014; pp 61-67. DOI: 10.1007/978-1-49391289-6_4. 